\title{
Post-endodontic Flare-ups after a Single-visit Treatment Using the FUI Scoring Method and Associated Factors: A Clinical Prospective Study
}

\author{
Christia Aoun ${ }^{1}$, Nada El Osta ${ }^{2}$, Alfred Naaman ${ }^{3}$, Carla Zogheib ${ }^{4}$, Issam Khalii ${ }^{5}$
}

\begin{abstract}
Aim: Flare-ups following a root canal treatment are still a major problem both to the patient and to the clinician. Its definition, etiology, incidence, and risk factors have been the subject of long-standing debate. We conducted this study to investigate the incidence of flare-ups after a singlevisit treatment and to identify the factors associated with the flare-up index (FUI).

Materials and methods: All patients treated by postgraduate residents in endodontic specialty at Saint Joseph University of Beirut from June 2018 to January 2019 were invited to participate in the study. After a routine root canal treatment, patients were given a questionnaire to fill after 24 hours -48 hours -7 days, covering a postoperative assessment of symptoms using the visual analogue scale (VAS) and FUI. Patients who experienced a severe postoperative pain and/or swelling were identified and categorized as having a flare-up.

Results: A total of 423 patients (age: $39.76 \pm 12.428$ years) were included in the study. The incidence of flare-up was $1.9 \%$. The mean FUI was $5.94 \pm 5.646$ and was highly correlated with the VAS score $(p<0.001)$. The factors that significantly influenced the occurrence of flare-ups were: pulpal diagnosis $(p<0.001)$, preoperative drug intake $(p<0.001)$, preoperative symptoms ( $>24$ hours) before treatment $(p<0.001)$, and tooth type $(p=0.013)$.

Conclusion: FUl should be used in further studies to confirm our results since it is a valid quantitative method to assess this clinical phenomenon. Clinical relevance: Endodontists should take into consideration the diagnosis and the history of preoperative symptoms since it plays an important role in predicting the occurrence of flare-ups and the success of the treatment.

Keywords: Endodontic treatment, Flare-up, Pain, Single-visit RCT, Swelling.

The Journal of Contemporary Dental Practice (2019): 10.5005/jp-journals-10024-2658
\end{abstract}

\section{INTRODUCTION}

An endodontic flare-up following a root canal treatment is still an unfortunate and distressful complication both to the patient and to the clinician despite remarkable developments of endodontic technologies. Patients might even consider postoperative complications as a proof to estimate clinician's skills. ${ }^{1}$ The prevalence of a postoperative pain or flare-up is, therefore, one of the influencing factors when making a clinical decision. ${ }^{2}$ The "acute exacerbation" of clinical symptoms involves a number of aspects related to local tissue changes, microbial factors, immunological phenomena, psychological factors, and other entities. ${ }^{3}$ The main characteristics are the occurrence of a pain and/or swelling that is of such severity that it disrupts the patient's lifestyle. ${ }^{1}$ In the endodontic literature, the exact definition of the flare-up differs from one study to another, which makes the comparison of their results very challenging. ${ }^{4}$ If some articles focus only on pain, ${ }^{5,6}$ others explain the flare-up as being the appearance of an intense pain, or swelling, or the combination of both. ${ }^{1,4,7}$ The absence of any gold standard and the lack of an exact definition of the flare-up resulted in estimated frequency differences from as low as $1.5 \%$ to as high as $20 \%{ }^{8,9}$ In addition, there is no unified opinion as to the reasons for a flare-up progression. This etiologic phenomenon may be attributed to various factors, including treatment procedures (chemical or mechanical injuries such as apical extrusion of debris), microbiologic factors, and host factors. ${ }^{10,11}$ A number of risk factors have been largely discussed in the literature regarding the prevalence of flare-ups. These factors include the age, gender, tooth type, use of analgesics and antibiotics, pulpal status, preoperative
1,3-5Department of Endodontics, School of Dentistry, Saint Joseph University of Beirut, Beirut, Lebanon

${ }^{2}$ Department of Prosthetic Dentistry, School of Dentistry, Saint Joseph University of Beirut, Beirut, Lebanon; Department of Public Health, School of Medicine, Saint Joseph University of Beirut, Beirut, Lebanon; Centre de Recherche en Odontologie Clinique, University of Clermont Auvergne, Clermont-Ferrand, France

Corresponding Author: Christia Aoun, Department of Endodontics, School of Dentistry, Saint Joseph University of Beirut, Beirut, Lebanon, Phone: +961 70366837, e-mail: aounchristia@gmail.com

How to cite this article: Aoun C, Osta N El, et al. Post-endodontic Flareups after a Single-visit Treatment Using the FUI Scoring Method and Associated Factors: A Clinical Prospective Study. J Contemp Dent Pract 2019;20(9):1033-1040.

Source of support: This work was funded by the Medical Research Council of Saint-Joseph University of Beirut (grant number: FMD129). The authors would like to thank the staff of the Department of Endodontics at the School of Dentistry at Saint Joseph University of Beirut, whose collaboration made this study possible.

Conflict of interest: None

symptoms, and the presence of periapical radiolucency. ${ }^{1,12-16}$ With the introduction of Niti endodontic instruments, some recent studies assessed the effect of using rotary or reciprocating instruments on postoperative pain. . $^{17,18}$

Postoperative pain is one of the major factors that can have a detrimental effect on the quality-of-life of patients submitted to 
root canal treatment. Visual analogue scale (VAS) is widely used as a result of its valid and reliable ratio scale to measure pain. ${ }^{7}$ Siqueira defines the flare-up as a severe pain and/or swelling after intra-canal procedures. ${ }^{18}$ The flare-up index (FUI), suggested by Rimmer, is a quantitative method that use a standardized questionnaire in which a numeric value can be used to define the existence and severity of the flare-ups. ${ }^{19}$ Although there is abundant information in the literature, it is a challenge to conclude the frequency of flare-ups and to indicate factors that affect them.

The aims of this study were therefore to assess the postendodontic flare-ups after a single-visit treatment using a FUI scoring method and to identify the factors associated.

\section{Materials and Methods}

\section{Study Population}

It was a clinical prospective study conducted at the Department of Endodontics at Saint Joseph University of Beirut. The protocol was approved by the Ethics Committee (USJ-2018-109) and a written informed consent was obtained. All patients aged between 18 and 65 years who had received a nonsurgical primary root canal treatment in one session from June 2018 to January 2019 were invited to participate in the study. Patients with single or multi-root teeth that required a primary endodontic therapy and had not undergone an emergency treatment were included. Only one tooth per patient was selected because multiple treated teeth from the same patient could not be assumed to behave in the same way. Root canal treatments were completed by endodontic postgraduate students. Patients with medical conditions that may alter the healing process, cases of cellulitis, or acute apical abscess requiring incision and drainage were excluded. Teeth with an indication for root canal retreatment, iatrogenic mishaps (intra-canal instrument fracture, missed canals, transportation, and perforation), internal or external resorption, and teeth with anatomic abnormality and tooth with a severe curvature superior to 25 degree were excluded. Teeth with sinus tracts were also excluded because it is believed that the presence of fistula removes the pressure, and by providing drainage, it acts as a security against acute exacerbation.

\section{Data Records}

Prior to treatment, the following data for each patient were recorded: age, gender, tooth type, history of preoperative symptoms (pain and/or swelling $>24$ hours before treatment and within 24 hours before treatment), medication taken in the 24 hours prior to treatment (analgesics or antibiotics), pulpal, and periradicular diagnosis.

The diagnosis was based on AAE Consensus Conference Recommended Diagnostic Terminology ${ }^{20}$ and established on an investigation of the main complaint, the dental history, the radiographic observation, the pulp test using cotton and an icing spray (Endo-Frost, Coltene Whaledent, Langenau, Germany), and the examination of the tooth (pocket probing, palpation, vertical and horizontal percussion). For pulpal diagnosis, the classification included normal vital pulp (symptom-free with a normal response to pulp testing, lesions that extend to the pulp but show no symptom of pulpitis still requires an endodontic treatment owing to an extensive pulpal exposure and intentional endodontic treatment done for prosthodontic reasons), irreversible pulpitis, asymptomatic irreversible pulpitis, necrotic pulp (if no bleeding was present following access preparation). For the non-vital teeth, teeth that presented a loss of lamina dura and periodontal ligament space $>2 \mathrm{~mm}$ were categorized as having lesions of endodontic origin (LEO). Radiological data were evaluated and the periapical diagnosis was classified as: pulp necrosis without periapical lesion; pulp necrosis with periapical lesion.

\section{Endodontic Procedure}

After local anesthesia and rubber dam isolation, access cavity and straight-line access preparations were performed by the residents of the Department of Endodontics. Canal entrances were scouted with a size $10 \mathrm{~K}$ file (Dentsply Maillefer) using lubricant. Working length was recorded with an electronic apex locator (Root ZX; J Morita, Tokyo, Japan). Chemo-mechanical preparation was performed using one of the two nickel-titanium ( $\mathrm{NiTi}$ ) instrumentation systems: continuous rotation or reciprocation. Files were used with an endodontic motor (X-Smart, Dentsply Maillefer), at the suggested settings and manufacturer's recommendations. Apical patency was maintained during preparation. Irrigation was done using $2.5 \% \mathrm{NaOCl}$ in standard needle irrigation and with and $17 \%$ ethylenediaminetetraacetic acid (EDTA). Root canals were dried with sterile paper points and then obturated with gutta percha and a zincoxide eugenol sealer using warm vertical compaction. The access cavity was filled with a temporary seal, Cavit (EspePremier, Norriston, PA, USA). Finally, the occlusion was adjusted using a wheel diamond bur. At the end of the visit, the patient was given instructions for postoperative care. The instructions stated that, if patients were experiencing pain, they are advised to take a nonsteroidal anti-inflammatory drug ( $400 \mathrm{mg}$ of ibuprofen) and repeat every 6 hours if they experienced pain. ${ }^{21}$

\section{Postoperative Assessment of Pain/Flare-ups}

A questionnaire was given to the participants to assess the postendodontic symptoms (pain and/or swelling). The existence and severity of acute exacerbation of symptoms was assessed using the flare-up index (FUI) - the dependent variable of the study (Table 1). This index contains questions related to symptoms and signs happening after the treatment (1-7 days): pain, swelling, analgesics taken, emergency visits provided, and systemic involvement. Each question has a specific value range and the total score varies from 0 to 45 . To express the degree of pain intensity after 24 hours, 48 hours, and 7 days posttreatment, patients were instructed to fill the visual analogue scale (VAS) with 0 for "no pain" and 100 for "unbearable pain."14,15 This score was converted to a 4 categorical scores with none (0); slight (1-3); moderate (4-6); and severe (7-10). ${ }^{22,23}$ Patients were asked to return the form back one week later or to be called by phone if they were unable to come back.

\section{Statistical Analyses}

The statistical analyses were performed using SPSS for Windows (Chicago, USA, version 25.0). The level of significance was set at $p \leq 0.05$. Kolmogorov-Smirnov tests were used to assess the normality distribution of continuous variables. The primary outcome variable of the study was the continuous FUI score. The categorization of patients having or not having a flare-up was done using the definition of Siqueira (experienced severe postoperative pain and/or swelling) to determine the incidence of flare-ups. ${ }^{11}$ The association between FUI score, flare-up, VAS score, and postoperative edema were evaluated using Mann-Whitney and Kruskal-Wallis tests.

Univariate analyses were performed to assess the predictor factors (age, gender, tooth type, history of preoperative symptoms, 
Table 1: The flare-up index questionnaire

\begin{tabular}{ll}
\hline & FUl range \\
\hline Existence of pain after the first visit & $0-1$ \\
The number of days with pain $\times$ pain degree/day** & $0-21$ \\
How many days were analgesics taken? & $0-7$ \\
How many times emergency treatment was needed? & $0-7$ \\
Does the pain still exist and in what degree? & $0-3$ \\
Are analgesics still being taken? & $0-1$ \\
Did swelling appear and to what degree?*** & $0-3$ \\
Existence of mouth limitation of mouth opening & $0-1$ \\
(trismus) & \\
Systemic involvement (temperature rising, fatigue) & $0-1$ \\
Total score & $0-45$
\end{tabular}

*Each positive answer in the parameters shown was scored in the ranges listed

**Degrees of pain: no pain (0); slight pain (1), moderate pain (2), severe pain (3). For example, severe pain for a period of 2 days, followed by moderate pain the next day, then by slight pain for another 2 days and no further pain give a total value in this line as shown: 2 days $\times 3$ (third-degree pain) +1 day $\times 2$ (second-degree pain) +2 days $\times 1$ (first-degree pain) +2 days $\times 0$ (no pain) $=$ total FUl value of 10 in this example

***Degrees of swelling: no swelling (0), slight to hardly noticeable (1), moderate (2), severe to face asymmetry (3)

medication taken in the 24 hours prior to treatment, pulpal diagnosis, tooth type, and instrumentation systems) associated with FUl. Student's $t$ tests and Mann-Whitney tests were used to compare continuous variables between two groups. Analysis of variance and Kruskal-Wallis tests were conducted to compare continuous variables between three or more groups. Predictive variables with a $p<0.200$ for univariate analyses were included in the multivariate model. Highly correlated variables were not included in the same multivariate model. Finally, two multiple regression analysis models were performed. The first model included: tooth type, pulpal diagnosis, preoperative symptoms within 24 hours before treatment, and preoperative symptoms $>24$ hours before treatment. The second model includes tooth type, pulpal diagnosis, and preoperative drug use.

\section{Results}

\section{Description of the Sample}

An estimated 445 patients consented to participate in this study: 11 patients did not properly filled questionnaires and 11 did not answer phone calls (95\% response rate). Finally, 423 patients (237 men and 186 women) were included (Table 2).

The teeth were mainly molars (47.1\%). Pulpal diagnosis was necrosis (40.9\%), irreversible symptomatic pulpitis (20.8\%), irreversible asymptomatic pulpitis (23.9\%), and normal pulp (14.4\%). Apical lesion was present at $66.5 \%$ of the necrotic teeth. A total of $34.5 \%$ of participants had a history of pain with or without edema before 24 hours preoperatively. Of the participants, $31.9 \%$ had symptoms (pain type with or without edema) in the 24 hours before endodontic treatment. Endodontic NiTi instruments used were continuous rotation systems in $45.4 \%$ of the cases and reciprocating systems in $54.6 \%$ of the cases. An estimated $62.6 \%$ of the patients did not take a premedication (Table 2).
Table 2: Description of the study population before endodontic treatment

\begin{tabular}{|c|c|c|}
\hline & Number & Percentage \\
\hline \multicolumn{3}{|l|}{ Gender } \\
\hline Men & 237 & 56.0 \\
\hline Women & 186 & 44.0 \\
\hline \multicolumn{3}{|l|}{ Age } \\
\hline $18-39$ years & 205 & 48.5 \\
\hline $40-65$ years & 218 & 51.5 \\
\hline \multicolumn{3}{|l|}{ Teeth location } \\
\hline Upper anterior teeth & 60 & 14.2 \\
\hline Lower inferior teeth & 48 & 11.3 \\
\hline Upper premolars & 59 & 13.9 \\
\hline Lower premolars & 57 & 13.5 \\
\hline Upper molars & 114 & 27.0 \\
\hline Lower molars & 85 & 20.1 \\
\hline \multicolumn{3}{|l|}{ Pulpal diagnosis } \\
\hline Normal pulp & 61 & 14.4 \\
\hline Symptomatic irreversible pulpitis & 88 & 20.8 \\
\hline Asymptomatic irreversible pulpitis & 101 & 23.9 \\
\hline Pulpal necrosis & 173 & 40.9 \\
\hline \multicolumn{3}{|l|}{ Periradicular diagnosis $(n=173)$} \\
\hline Pulp necrosis with periapical lesion & 115 & 66.5 \\
\hline Pulp necrosis without periapical lesion & 58 & 33.5 \\
\hline \multicolumn{3}{|c|}{ Preoperative symptoms $>24$ hours before treatment } \\
\hline Yes & 146 & 34.5 \\
\hline No & 277 & 65.5 \\
\hline \multicolumn{3}{|c|}{ Preoperative symptoms $<24$ hours before treatment } \\
\hline Oui & 135 & 31.9 \\
\hline Non & 288 & 68.1 \\
\hline \multicolumn{3}{|l|}{ Premedication drug } \\
\hline Analgesic & 74 & 17.5 \\
\hline Antibiotic & 47 & 11.1 \\
\hline Both & 37 & 8.7 \\
\hline None & 265 & 62.6 \\
\hline \multicolumn{3}{|l|}{ Endodontic instrumentation system } \\
\hline Rotary instruments & 192 & 45.4 \\
\hline Reciprocating instruments & 231 & 54.6 \\
\hline
\end{tabular}

\section{Postoperative Symptoms}

The mean flare-up index was $5.94 \pm 5.646$ and ranged from 0 to 34 . The overall incidence of flare-ups was $1.9 \%$ (8 of 423 cases). Only $4.7 \%$ had postoperative edema. The VAS significantly decreased over time (at 24 hours: $3.56 \pm 2.533$; at 48 hours: $2.42 \pm 2.257$; at 7 days: $0.42 \pm 1.068 ; p<0.001)$. The mean FUI score was positively correlated with VAS score at 24 hours $(p<0.001), 48$ hours $(p<0.001)$, and 7 days $(p<0.001)$, with flare-ups $(p<0.001)$ and with postoperative edema $(p<0.001)$ (Table 3$)$.

\section{Univariate Analyses of the Association with FUI}

Our study revealed that FUI was not significantly associated with gender $(p=0.417)$, age $(p=0.287)$, and endodontic instrumentation system $(p=0.694)$ (Table 4$)$.

FUI was significantly associated with pulpal diagnosis ( $p<0.001)$; it was smaller after treatment of teeth with normal 
Table 3: Association among flare-up index, flare-up, VAS score, and postoperative edema

\begin{tabular}{|c|c|c|c|c|}
\hline & $N$ & Mean flare-up index & Standard-deviation & $p$ \\
\hline \multicolumn{5}{|l|}{ Flare-up } \\
\hline Yes & 8 & 27.00 & 3.117 & \multirow[t]{2}{*}{$<0.001$} \\
\hline No & 415 & 5.53 & 4.857 & \\
\hline \multicolumn{5}{|c|}{ Postoperative edema } \\
\hline Yes & 20 & 17.25 & 5.665 & \multirow[t]{2}{*}{$<0.001$} \\
\hline No & 403 & 5.37 & 5.026 & \\
\hline \multicolumn{5}{|l|}{ VAS 24 hours } \\
\hline None & 69 & $0.57^{\mathrm{a}}$ & 1.843 & \multirow[t]{5}{*}{$<0.00$} \\
\hline $1-3$ slight & 149 & $3.23^{b}$ & 2.414 & \\
\hline 4-6 moderate & 147 & $7.54^{c}$ & 3.713 & \\
\hline 7-9 severe & 53 & $14.25^{d}$ & 4.735 & \\
\hline 10 unbearable & 5 & $25.40^{\mathrm{e}}$ & 6.542 & \\
\hline \multicolumn{5}{|l|}{ VAS 48 hours } \\
\hline None & 119 & $0.88^{\mathrm{a}}$ & 1.158 & \multirow[t]{5}{*}{$<0.001$} \\
\hline $1-3$ slight & 168 & $4.79^{b}$ & 2.762 & \\
\hline 4-6 moderate & 120 & $10.55^{c}$ & 3.977 & \\
\hline 7-9 severe & 12 & $18.67^{d}$ & 6.140 & \\
\hline 10 unbearable & 4 & $27.75^{e}$ & 4.500 & \\
\hline \multicolumn{5}{|l|}{ VAS 7 days } \\
\hline None & 332 & $3.78^{\mathrm{a}}$ & 3.337 & \multirow[t]{4}{*}{$<0.001$} \\
\hline $1-3$ slight & 78 & $12.77^{\mathrm{b}}$ & 4.181 & \\
\hline 4-6 moderate & 10 & $17.50^{c}$ & 5.701 & \\
\hline 7-9 severe & 3 & $28.67^{d}$ & 5.033 & \\
\hline
\end{tabular}

${ }^{\mathrm{a}-\mathrm{e}}$ Indicate the presence of significant difference according to multiple comparisons tests.

Table 4: Univariate analyses of the factors associated with the FUI

\begin{tabular}{|c|c|c|c|c|}
\hline & $N$ & Mean FUI & Standard-deviation & $p$ \\
\hline \multicolumn{5}{|l|}{ Gender } \\
\hline Male & 237 & 5.74 & 5.137 & 0.417 \\
\hline Female & 186 & 6.19 & 6.240 & \\
\hline \multicolumn{5}{|l|}{ Age } \\
\hline $18-39$ years & 205 & 5.63 & 5.188 & 0.287 \\
\hline $40-65$ years & 218 & 6.22 & 6.043 & \\
\hline \multicolumn{5}{|l|}{ Teeth type } \\
\hline Maxillary anterior & 60 & $7.60^{b}$ & 5.901 & 0.025 \\
\hline Mandibular anterior & 48 & $4.42^{\mathrm{a}}$ & 4.907 & \\
\hline Maxillary premolar & 59 & $6.53^{a, b}$ & 5.776 & \\
\hline Mandibular premolar & 57 & $5.74^{\mathrm{a}, \mathrm{b}}$ & 5.380 & \\
\hline Maxillary molar & 114 & $5.09^{a, b}$ & 4.927 & \\
\hline Mandibular molar & 85 & $6.48^{a, b}$ & 6.509 & \\
\hline \multicolumn{5}{|l|}{ Location of the tooth } \\
\hline Mandible & 233 & 6.10 & 5.491 & 0.513 \\
\hline Maxilla & 190 & 5.74 & 5.839 & \\
\hline \multicolumn{5}{|l|}{ Teeth group } \\
\hline Anterior & 108 & 6.19 & 5.683 & 0.686 \\
\hline Premolar & 116 & 6.14 & 5.575 & \\
\hline Molar & 199 & 5.68 & 5.684 & \\
\hline \multicolumn{5}{|l|}{ Pulpal diagnosis } \\
\hline Normal pulp & 61 & $2.75^{\mathrm{a}}$ & 3.654 & $<0.001$ \\
\hline Symptomatique irreversible pulpitis & 88 & $5.12^{\mathrm{b}}$ & 5.356 & \\
\hline Asymptomatique irreversible pulpitis & 101 & $3.55^{\mathrm{a}, \mathrm{b}}$ & 3.716 & \\
\hline Pulpal necrosis & 173 & $8.86^{\mathrm{c}}$ & 5.928 & \\
\hline
\end{tabular}




\begin{tabular}{|c|c|c|c|c|}
\hline & $N$ & Mean FUI & Standard-deviation & $p$ \\
\hline Vital pulp & 250 & 3.91 & 4.437 & $<0.001$ \\
\hline Pulp necrosis & 173 & 8.86 & 5.928 & \\
\hline \multicolumn{5}{|l|}{ Periradicular diagnosis $(n=173)$} \\
\hline Pulp necrosis with periapical lesion & 115 & 8.95 & 6.364 & 0.788 \\
\hline Pulp necrosis without periapical lesion & 58 & 8.69 & 4.999 & \\
\hline \multicolumn{5}{|c|}{ Preoperative symptoms $>24$ hours before treatment } \\
\hline Yes & 146 & 8.46 & 6.983 & $<0.001$ \\
\hline No & 277 & 4.61 & 4.240 & \\
\hline \multicolumn{5}{|c|}{ Preoperative symptoms within 24 hours before treatment } \\
\hline Yes & 135 & 6.48 & 5.795 & 0.088 \\
\hline No & 288 & 5.68 & 5.566 & \\
\hline \multicolumn{5}{|l|}{ Premedication drug } \\
\hline Analgesic & 74 & $6.62^{\mathrm{a}, \mathrm{b}}$ & 6.707 & $<0.001$ \\
\hline Antibiotic & 47 & $7.66^{\mathrm{b}, \mathrm{c}}$ & 6.015 & \\
\hline Both & 37 & $9.22^{c}$ & 5.697 & \\
\hline None & 265 & $4.98^{\mathrm{a}}$ & 4.970 & \\
\hline \multicolumn{5}{|l|}{ Endodontic instrumentation system } \\
\hline Rotary instruments & 192 & 5.82 & 5.482 & 0.694 \\
\hline Reciprocating instruments & 231 & 6.03 & 5.788 & \\
\hline
\end{tabular}

${ }^{a-c}$ Indicate the presence of significant difference according to multiple comparisons tests.

pulp, intermediate in the case of asymptomatic irreversible and symptomatic irreversible pulpitis, and higher after treatment of necrotic teeth. Treating a necrotic tooth with or without apical lesion was not significantly associated with FUI values $(p=0.788)$.

The FUI was not significantly different between participants who did or did not experience painful symptoms within 24 hours before endodontic treatment ( $p=0.088$ ). On the contrary, FUI was significantly associated with preoperative pain in participants who had a history of preoperative symptoms $>24$ hours before treatment $(p<0.001)$.

Finally, FUl was significantly associated with preoperative drug use $(p<0.001)$; for instance, participants who took antibiotics associated with analgesics preoperatively had a higher FUI, followed by participants taking painkillers or antibiotics; participants who took nothing had the lowest FUI $(p<0.001)$.

\section{Multivariate Analyses of the Association with FUI}

Table 5 illustrates the multivariate analysis after controlling confounding factors. It showed that pulpal diagnosis $(p<0.001)$, preoperative drug intake $(p<0.001)$, presence of preoperative symptoms ( $>24$ hours) before treatment $(p<0.001)$ and upper anterior teeth $(p=0.013)$ remain associated with FUI score. The factors associated with FUI in order of importance were necrotic teeth $(r=0.447)$, preoperative pain $(r=0.341)$, preoperative medication $(r=0.214)$, and type of teeth $(r=0.121)$.

\section{Discussion}

This prospective study presents the incidence of a flare-up following a single-visit endodontic treatment and highlights the risk factors that may affect its occurrence based on FUI numerical scores. The low incidence of flare-ups (1.9\%) reported in our study was similar to the incidence rate of $1.8 \%$ for single-visit endodontics reported by Trope, who also used a similar definition of flare-up. ${ }^{24}$ Variability in the definition of flare-up and the absence of any gold standard for flare-up assessment resulted in a big heterogeneity in the endodontic literature. For these reasons, measuring the clinical findings of the flare-up phenomenon that includes pain or swelling with FUI values may be helpful. ${ }^{4}$

Our findings revealed a correlation between FUI scores and VAS values at 24 hours/48 hours and 7 days. Hence, FUI based on a developed questionnaire describes all of the parameters concerning the flare-up and enables the patient to describe it as correctly as possible. FUI can be used as a valid and reproducible guideline to measure and study more this phenomenon. Moreover, the decrease of the VAS values is in agreement with the findings of other studies. ${ }^{25,26}$

Flare-ups are multifactorial and there is no unified opinion as to the reasons for its occurrence. However, this undesirable complication can be predicted if risk factors can be identified in a patient. In the present study, an analysis regarding the influence of age, gender, and instrumentation did not show significant differences in FUI values.

A major finding is that pulp status is significantly related to flareups: compared to vital teeth, necrotic pulp teeth have are more likely to develop a flare-up ( $p<0.001)$. Siqueira et al. showed that the high incidence rate of flare-ups in such cases of infection may be related to the presence of bacteria and their products that can be extruded into the periapical region during treatment. ${ }^{11}$ Concerning the presence of periapical radiolucency, the difference in the FUI values between the groups of necrotic teeth with or without periapical lesions was not significant. Our results were consistent with the study carried out by Alaçam and Tinaz, who also used the FUI as a tool for assessment. ${ }^{4}$ Much debate exists regarding the influence of periapical diagnosis. Some studies have shown that the absence of apical radiolucency is a significant predictor of a flare-up. ${ }^{15,27}$ This may be explained by the inadequate space available for the dispersal of the pressure due to acute periradicular inflammation. On the other hand, other studies indicated that cases with a apical lesion had a higher risk of developing pain and flare-ups. ${ }^{14,28}$ Therefore, it may be logical to solve this dilemma by analyzing the 
Table 5: Multiple regression analyses of factors associated with FUI

\begin{tabular}{|c|c|c|c|c|c|c|c|}
\hline \multirow[b]{2}{*}{ Mode } & & \multicolumn{2}{|c|}{$\begin{array}{c}\text { Unstandardized } \\
\text { coefficients }\end{array}$} & \multirow{2}{*}{\multicolumn{2}{|c|}{$\begin{array}{c}\text { Standardized } \\
\text { coefficients } \\
\text { Beta }\end{array}$}} & \multirow[b]{2}{*}{$p$} & \multirow{2}{*}{$\begin{array}{l}\text { Partial } \\
\text { correlation }\end{array}$} \\
\hline & & Beta & Standard error & & & & \\
\hline \multirow[t]{4}{*}{1} & Maxillary anterior teeth/other teeth types & 0.979 & 0.671 & -0.061 & 1.458 & 0.145 & 0.071 \\
\hline & Vital pulp/pulp necrosis & 1.624 & 0.159 & 0.425 & 10.221 & 0.000 & 0.447 \\
\hline & History of pain/swelling $>24$ hours & 3.749 & 0.505 & -0.316 & 7.422 & 0.000 & 0.341 \\
\hline & History of pain/swelling $<24$ hours & 0.296 & 0.518 & -0.024 & 0.571 & 0.568 & 0.028 \\
\hline \multirow[t]{3}{*}{2} & Maxillary anterior teeth/other teeth types & 1.910 & 0.764 & 0.118 & 2.500 & 0.013 & 0.121 \\
\hline & Vital pulp/pulp necrosis & 1.571 & 0.166 & 0.411 & 9.466 & 0.000 & 0.420 \\
\hline & Premedication drug & 2.247 & 0.502 & 0.193 & 4.479 & 0.000 & 0.214 \\
\hline
\end{tabular}

presence and the size of periapical lesions with a greater certainty by using imaging techniques with a better sensitivity, such as cone beam computed tomography (CBCT).

The vast majority of studies have shown that the presence of a preoperative symptoms is a significant potential influencing risk factor for flare-ups. ${ }^{1,5,8,13,27,29}$ In the present study, the magnitude of association of preoperative pain with flare-up have shown a statistical significance when we took into consideration the duration of pain history similarly to $\mathrm{Ng}$ et al. and Polycarpou et al. ${ }^{12,30} \mathrm{On}$ the basis of our results, FUI values were found to be higher when patients experienced symptoms in the past up to 24 hours before the treatment. Perhaps an important explanation of this finding is that preexisting pulpal and/or periradicular pain, resulting from acute inflammation of the associated anatomic structures, can cause central neuroplastic changes in the dorsal horn and an increase in the size of the receptive field of A-delta fibers. ${ }^{29}$ It may also be hypothesized that the patients experiencing a history of pain may have a lower pain threshold or they may have been psychologically preconditioned to postobturation pain. ${ }^{3,23,28}$ Therefore, a practitioner should pay attention to this history of previous pain that adds another dimension in diagnosis.

The variable "premedication drug" is very illustrative of the clinical situation in the 24 hours before the treatment because patients presenting acute symptoms and coming on emergency visits are more likely to be taking drugs. This is very common especially in our Lebanese population where the prevalence of self-medication is alarmingly high. ${ }^{31,32}$

We found it most important in our study that higher values of FUI were found in patients taking analgesics and/or antibiotics. Those results are similar to those given by Walton and Fouad, ${ }^{1}$ who explained the fact that the severity of the pathosis is proportional to the increase of post-treatment problems. Interestingly, we found that antibiotics did not seem to have a preventive role in the occurrence of flare-ups. The relationship between flare-ups and antibiotics has been a subject of interest and conflicting findings. Most of recent studies and recommendations showed that antibiotics do not provide clinical prophylactic effects on postoperative exacerbations and should not be recommended as a routine protocol before treatment. ${ }^{33,34}$ The abusive use of antibiotics in situations where their use is not indicated is an international concern because of the emergence of antibioticresistant bacterial strains within both the individual and the community. ${ }^{35}$

We found that the maxillary anterior teeth had the highest FUI scores. This result could be explained by the fact that postgraduate endodontic residents mainly treat molars. Also, they treat some anterior teeth usually referred to the department owing to related difficulties and considerable pathologies (necrotic teeth with preoperative pain or swelling).

Our longitudinal study has a prospective nature, which is ranked as the second best power design because it allows researchers to have more control over the environment compared with retrospective cohort studies. ${ }^{2}$ Gaining an insight into the risk factors and clinical details of patients who have increased likelihood of developing a flare-up is valuable for clinicians and immediately useful in practical applications of patient care. A limitation to this study is the absence of the psychological aspect of pain that is considered as an essential component to the evaluation of oral health-related quality-of-life in recent studies. ${ }^{36,37}$ Other factors such as retreatment cases and patient's medical condition should be studied based on the FUI scoring method.

A short- or long-term outcome of endodontic treatment may have a genetic answer or possibly a differential heritable susceptibility to the initiation and experience of pain. ${ }^{38-40}$ This observation offers a promising field for future research in genetics and molecular microbiology.

\section{Conclusion}

Within the limitation of this study, a flare-up following a singlevisit endodontic treatment was investigated, and the incidence determined was minimal (1.9\%). There is strong evidence that the FUI was highly correlated with the VAS pain scale. FUI is a valid, reliable, and standardized tool to assess the flare-up phenomenon in future studies.

Our findings clearly demonstrate that strong predictive factors associated with a flare-up were necrotic teeth and history of preoperative pain. In addition, preoperative medication and upper anterior teeth were also associated with flare-ups. Endodontists should take risk factors into consideration before treatment in order to prevent the occurrence of flare-ups and improve patients quality-of-life after treatment. Further studies in the microbiological and genetic fields are recommended for further establishing a longterm outcome and predictive factors of single-sitting endodontic treatment.

\section{Ethical Approval}

The protocol of the study was approved by the Committee of Ethics at Saint Joseph University of Beirut (Project no. USJ-2018-109). All procedures were in accordance with the ethical standards of the Institutional Research Committee and with the 1964 Helsinki 
declaration and its later amendments or comparable ethical standards.

\section{Informed Consent}

Written informed consent was obtained from all individual participants included in the study.

\section{Disclaimers}

The views expressed in the submitted article are our own and not an official position of the institution or the funder.

\section{Authors' Contributions}

CA, NEO, AN, CZ, IK contributed with the conception and design, analysis, and interpretation of data. CA, NEO contributed with the acquisition of data. CA, NEO involved in drafting the manuscript. CA, NEO, IK revised critically the manuscript for important intellectual content. All authors read and approved the final manuscript.

\section{References}

1. Walton R, Fouad A. Endodontic interappointment flare-ups: a prospective study of incidence and related factors. J Endod 1992 Apr;18(4):172-177. DOI: 10.1016/S0099-2399(06)81413-5.

2. Sathorn C, Parashos $P$, et al. The prevalence of postoperative pain and flare-up in single- and multiple-visit endodontic treatment: a systematic review. Int Endod J 2008 Feb;41(2):91-99.

3. Seltzer S. Pain in endodontics. J Endod 1986 Jan;12(10):505-508. DOI: 10.1016/S0099-2399(86)80207-2.

4. Alaçam T, Tinaz AC. Interappointment emergencies in teeth with necrotic pulps. J Endod 2002 May;28(5):375-377. DOI: 10.1097/00004770-200205000-00007.

5. Glennon JP, Ng Y-L, et al. Prevalence of and factors affecting postpreparation pain in patients undergoing two-visit root canal treatment. Int Endod J 2004 Jan;37(1):29-37. DOI: 10.1111/j.13652591.2004.00748.x.

6. Harrison JW, Baumgartner JC, et al. Incidence of pain associated with clinical factors during and after root canal therapy. Part 2 Postobturation pain. J Endod 1983 Oct;9(10):434-438. DOI: 10.1016/ S0099-2399(83)80259-3.

7. Tsesis I, Faivishevsky V, et al. Flare-ups after endodontic treatment: a meta-analysis of literature. J Endod 2008 Oct;34(10):1177-1181. DOI: 10.1016/j.joen.2008.07.016.

8. Imura N, Zuolo ML. Factors associated with endodontic flare-ups: a prospective study. Int Endod J 1995 Sep;28(5):261-265. DOI: 10.1111/j.1365-2591.1995.tb00311.x.

9. Morse DR, Koren LZ, et al. Asymptomatic teeth with necrotic pulps and associated periapical radiolucencies: relationship of flare-ups to endodontic instrumentation, antibiotic usage and stress in three separate practices at three different time periods. Int J Psychosom Off Publ Int Psychosom Inst 1986;33(1):5-87.

10. Seltzer S, Naidorf IJ. Flare-ups in endodontics: I. Etiological factors. 1985. J Endod 2004 Jul;30(7):476-481. DOI: 10.1097/00004770200407000-00005, ; discussion 475.

11. Siqueira JF, Rôças IN, et al. Incidence of postoperative pain after intracanal procedures based on an antimicrobial strategy. J Endod 2002 Jun;28(6):457-460. DOI: 10.1097/00004770-20020600000010.

12. Ng Y-L, Glennon JP, et al. Prevalence of and factors affecting postobturation pain in patients undergoing root canal treatment. Int Endod J 2004 Jun;37(6):381-391. DOI: 10.1111/j.1365-2591.2004. 00820.x.

13. Albashaireh ZS, Alnegrish AS. Postobturation pain after single- and multiple-visit endodontic therapy. A prospective study. J Dent 1998 Mar;26(3):227-232. DOI: 10.1016/S0300-5712(97)00006-7.
14. Iqbal $M, K u r t z E$, et al. Incidence and factors related to flare-ups in a graduate endodontic programme. Int Endod J 2009 Feb;42(2):99-104. DOI: 10.1111/j.1365-2591.2008.01461.x.

15. Onay EO, Ungor $M$, et al. The evaluation of endodontic flare-ups and their relationship to various risk factors. BMC Oral Health $2015 \mathrm{Nov}$ 14;15(1):142. DOI: 10.1186/s12903-015-0135-2.

16. Sun C, Sun J, et al. Pain after root canal treatment with different instruments: A systematic review and meta-analysis. Oral Dis 2018 Sep;24(6):908-919. DOI: 10.1111/odi.12854.

17. Hou X-M, Su Z, et al. Post endodontic pain following single-visit root canal preparation with rotary vs reciprocating instruments: a meta-analysis of randomized clinical trials. BMC Oral Health 2017 May 25;17(1):86. DOI: 10.1186/s12903-017-0355-8.

18. Siqueira JF. Microbial causes of endodontic flare-ups. Int Endod J 2003 Jul;36(7):453-463. DOI: 10.1046/j.1365-2591.2003.00671.x.

19. Rimmer A. The flare-up index: a quantitative method to describe the phenomenon. J Endod 1993 May;19(5):255-256. DOI: 10.1016/ S0099-2399(06)81304-X.

20. AAE. Consensus Conference Recommended Diagnostic Terminology. [Internet]. 2013 [cited 2018 Oct 9]. Available from: https:// www.aae.org/specialty/wp-content/uploads/sites/2/2017/07/ endodonticdiagnosisfall2013.pdf.

21. Smith EA, Marshall JG, et al. Nonsteroidal Anti-inflammatory Drugs for Managing Postoperative Endodontic Pain in Patients Who Present with Preoperative Pain: A Systematic Review and Meta-analysis. J Endod 2017 Jan;43(1):7-15. DOI: 10.1016/j.joen.2016.09.010.

22. Torabinejad $M$, Cymerman JJ, etal. Effectiveness of various medications on postoperative pain following complete instrumentation. J Endod 1994 Jul;20(7):345-354. DOI: 10.1016/S0099-2399(06)80098-1.

23. Segura-Egea JJ, Cisneros-Cabello R, et al. Pain associated with root canal treatment. Int Endod J 2009 Jul;42(7):614-620. DOI: 10.1111/j.1365-2591.2009.01562.x.

24. Trope M. Flare-up rate of single-visit endodontics. Int Endod J 1991 Jan;24(1):24-26. DOI: 10.1111/j.1365-2591.1991.tb00866.x.

25. Pasqualini $D$, Corbella $S$, et al. Postoperative quality of life following single-visit root canal treatment performed by rotary or reciprocating instrumentation: a randomized clinical trial. Int Endod J 2016 Nov;49(11):1030-1039. DOI: 10.1111/iej.12563.

26. Pak JG, White SN. Pain prevalence and severity before, during, and after root canal treatment: a systematic review. J Endod 2011 Apr;37(4):429-438. DOI: 10.1016/j.joen.2010.12.016.

27. Torabinejad $M$, Kettering JD, et al. Factors associated with endodontic interappointment emergencies of teeth with necrotic pulps.J Endod 1988 May;14(5):261-266. DOI: 10.1016/S0099-2399(88)80181-X.

28. Alves Vde O. Endodontic flare-ups: a prospective study. Oral Surg Oral Med Oral Pathol Oral Radiol Endod 2010 Nov;110(5):e68-e72. DOI: 10.1016/j.tripleo.2010.05.014.

29. Attar S, Bowles WR, et al. Evaluation of pretreatment analgesia and endodontic treatment for postoperative endodontic pain. J Endod 2008 Jun;34(6):652-655. DOI: 10.1016/j.joen.2008.02.017.

30. Polycarpou N, Ng Y-L, et al. Prevalence of persistent pain after endodontic treatment and factors affecting its occurrence in cases with complete radiographic healing. Int Endod J 2005 Mar;38(3):169178. DOI: 10.1111/j.1365-2591.2004.00923.x.

31. Saleh N, Awada S, et al. Evaluation of antibiotic prescription in the Lebanese community: a pilot study. Infect Ecol Epidemiol 2015 Jan 1;5(1):27094. DOI: 10.3402/iee.v5.27094.

32. Mouhieddine TH, OlleikZ, et al. Assessing the Lebanese population for their knowledge, attitudes and practices of antibiotic usage. J Infect Public Health 2015 Jan 1;8(1):20-31. DOI: 10.1016/j.jiph.2014.07.010.

33. Lindeboom JAH, Frenken JWH, et al. The role of preoperative prophylactic antibiotic administration in periapical endodontic surgery: a randomized, prospective double-blind placebo-controlled study. Int Endod J 2005 Dec;38(12):877-881. DOI: 10.1111/j.13652591.2005.01030.x.

34. American Association of Endodontists position statement: AAE guidance on the use of systemic antibiotics in endodontics. J Endod 2017 Sep;43(9):1409-1413. DOI: 10.1016/j.joen.2017.08.015. 
35. Cope AL, Francis N, et al. Systemic antibiotics for symptomatic apical periodontitis and acute apical abscess in adults. Cochrane Database Syst Rev 2018 Sep 27;9:CD010136. DOI: 10.1002/14651858.CD010136. pub3.

36. Oliveira PS, da Costa KNB, et al. Impact of root canal preparation performed by ProTaper Next or Reciproc on the quality of life of patients: a randomized clinical trial. Int Endod J 2018 Jul;55(2):139-148. DOI: 10.1111/iej.12990.

37. Chandraweera L, Goh K, et al. A survey of patients' perceptions about, and their experiences of, root canal treatment. Aust Endod J 2018 Oct;45(2):225-232. DOI: 10.1111/aej.12312.
38. Philpott R, Gulabivala K, et al. Prevalence, predictive factors and clinical course of persistent pain associated with teeth displaying periapical healing following nonsurgical root canal treatment: a prospective study. Int Endod J 2018 Oct;52(4): 407-415.

39. Elzaki WM, Ziada HM, et al. Gender and arch effects on the use of non-opioid analgesics for post endodontic pain reduction. Aust Endod J 2017 Oct;44(3):215-224.

40. Siqueira JF, Rôças IN. Present status and future directions in endodontic microbiology. Endod Top 2014;30(1):3-22. 